\title{
NURTURING FACTORS THAT PROMOTE MATHEMATICS ACHIEVEMENT IN MAINLAND CHINA
}

\author{
ZHA ZIXIU,* LIU PENGZHI $\dagger$ and TAO XIAOYONG $\ddagger$ \\ *Institute of Psychology, Chinese Academy of Sciences, P.O. Box 1603, Postcode 100012, \\ Beijing, China \\ †High School Attached to the People's University of China, No. 65 Haidian Road, \\ Beijing, China \\ ‡eijing Educational Institute, Beijing, China
}

\begin{abstract}
Thirty-five Olympians ( 33 males and 2 females) and their parents participated in this study. The instruments consisted of Olympians'/Parents' Questionnaires, Self-confidence and attitude attribute Scales, and the Inventory of Parental Influence. The main results were as follows. Most of the Olympians came from intellectual families (both parents occupied high-status positions and had high levels of education). Most of the families had one or two children (25.7\% were the only child in the family). Most Olympians studied in key middle schools and received instruction from teachers with excellent math backgrounds; more than half were enrolled in gifted classes in high schools. Most of the Olympians graduated from senior high school at the age of 17 or 18 and all had the highest grades ("excellent") in mathematics and most had "excellent/good" report card grades in all school subjects; however, they had few chances to learn to use computers. Most of the Olympians credit the Math Olympiad program with promoting the development of their math potential and producing positive changes in learning attitudes as well. (O) 1997 Elsevier Science Ltd. All rights reserved
\end{abstract}

\section{Introduction}

The International Math Olympiad (IMO) has a long worldwide history. In Mainland China, however, participation began in 1985 for middle school students (Zhou \& $\mathrm{Lu}, 1995$ ). In ten years the Chinese mathematics delegations achieved considerable success in the IMO competitions. To date they have won 39 gold medals, 17 silver medals, and 4 bronze medals. Five times they achieved championship team scores (three times the teams placed second). The development of adolescent mathematics talent in Mainland China has attracted wide interest and attention.

This research study is part of a series of cross-cultural investigations of Math Olympiad contestants in the United States, Taiwan China, Mainland China, and Japan. As a result of this 
project, it has been possible to probe into the development of adolescent mathematics talent. These studies have also been useful in learning how mathematical personnel in the different countries discover and foster the development of math talent.

\section{Methods and Procedures}

The sample consisted of 35 Mainland Chinese Math Olympians, including IMOs and Chinese Math Olympians (CMOs). The thirty-three males (94.3\%) and two females (5.7\%) came from seven large administrative areas and 16 cities in Mainland China, ranging from Heilongjiang in the north to Guangdong in the south, Xinjiang in the west, and Jiang Zhe in the east. While there were 35 families (total 70 parents), only 22 families and 41 parents returned the packet of instruments.

Four instruments were used in this study: Olympians' Questionnaire, Self-confidence and attitude attribute Scales, Parents' Questionnaire, and Inventory of Parental Influence scales (see Chapter 2). The Math Olympians were gathered in small groups and given the sets of instruments together with an explanation of what was required. The parents were mailed questionnaires with the expectation that they would return them upon completion. The data from the four instruments were recorded onto scantron pages and machine scored. All data were analyzed under standardized conditions.

\section{Results}

The results are organized into four sections. They are family background, school, math Olympiad program, and influencing factors.

\section{The Family Background}

The Olympians came mostly from intellectual families. The occupational status and educational attainment of the parents can be seen in Tables 5.1 and 5.2.

Most of the families ( $80 \%$ ) had only one or two children. The birth order of the Olympians in the family was as follows: first child (including only child), $42.8 \%$; second in the family, $42.8 \%$; the rest (third or fourth), 14.3\%. The average size of the families was 1.42 children.

During the early development of the Olympians, most of the families had many books in their homes (see Table 5.3). Furthermore, the majority of parents discovered their child's extraordinary math talent when their child was in primary or junior middle school (see Table 5.4).

Table 5.1

Occupation of Parents of Olympians (\%)

\begin{tabular}{lcccc}
\hline Parents & Intellectual & Worker & Farmer & Home labor \\
\hline Father & 85.7 & 8.6 & 5.7 & 0 \\
Mother & 68.6 & 20.0 & 8.6 & 2.8 \\
\hline
\end{tabular}


Table 5.2

Educational Attainment of Parents of Olympians (\%)

\begin{tabular}{lccc}
\hline Parents & College/above & $\begin{array}{c}\text { Middle school } \\
\text { graduate }\end{array}$ & $\begin{array}{c}\text { Primary school/ } \\
\text { under }\end{array}$ \\
\hline Father & 68.6 & 17.1 & 14.3 \\
Mother & 48.6 & 37.1 & 14.3 \\
\hline
\end{tabular}

Table 5.3

Books in the Olympians' Families (\%)

\begin{tabular}{lcc}
\hline Books & Olympians & Parents \\
\hline 1. Very few books (0-9) & 6.0 & 6.0 \\
2. A few books $(10-25)$ & 3.0 & 0 \\
3. One bookcase $(25-99)$ & 17.0 & 23.0 \\
4. Two bookcases $(100-249)$ & 5.7 & 18.0 \\
5. Three or more bookcases & 68.6 & 53 \\
\hline M & 4.29 & 4.11 \\
SD & 1.20 & 1.16 \\
\hline
\end{tabular}

Table 5.4

Age when Parent Discovered Child was Gifted (\%)

\begin{tabular}{lc}
\hline Different stages (age) & Percentage of children \\
\hline Preschool (ages 1-6) & 18 \\
Elementary (ages 7-11) & 35 \\
Jr. High (ages 12-15) & 41 \\
Sr. High (ages 16-18) & 6 \\
\hline
\end{tabular}

Eighty-nine percent of the Olympians could speak one foreign language, but no one else in their families spoke any foreign languages. More than half of the families $(51 \%)$ spoke standard Chinese (Mandarin); 49\% spoke another dialect. Most of the Olympians (97\%) spoke standard Chinese (Mandarin).

Only nine of the Olympians could play a musical instrument (25.7\%) and most of the members of their families did not play any instrument $(60 \%)$. However, in $35 \%$ of the families, one member played an instrument.

\section{School}

The Olympians mostly studied in key primary and middle schools (some of them were famous schools in the country). These schools paid careful attention to school reforms and raised teaching standards. The teachers involved in the Math Olympiad program had rich experiences to share with the students and also had more extensive math backgrounds. These Olympians did not have 
any access to gifted classes when they studied in primary school and only $30 \%$ were provided gifted classes in the junior middle school. However, $65 \%$ of the Olympians were enrolled in gifted classes in the senior middle schools.

Most of the Olympians scored "excellent" (highest grade) in their studies before graduation from middle school. One hundred percent scored "excellent" in mathematics, and $90 \%$ scored "excellent" in physics. Very few subjects scored "average," and there were no "poor" scores (see Table 5.5). Most of the Olympians (85.7\%) graduated from their senior middle schools at the age of 17 or 18 (see Table 5.6).

The Olympians had little chance to learn to use computers. None of them ever used a main frame computer, but some used microcomputers (see Table 5.7). On a five-point scale they estimated their level of computer literacy to be between mid-level and a rather low level $(M=2.57, \mathrm{SD}=.96)$.

Most of the Olympians graduated from middle school. Sixteen of them are studying at Beijing University; 14 are enrolled in Qinghua University (totaling 30 or $85.7 \%$ ). Five of the Olympians have graduated from universities and are studying for their MA or Ph.D. degrees (14.3\%). Those who graduated from middle school experienced no difficulties in being admitted to different universities. The universities, however, did not provide special programs or individualized opportunities for them.

\section{Math Olympiad Program}

The Olympians and their parents evaluated the Math Olympiad program. The overall evaluations were quite positive. Eighty-nine percent of the Olympians (and $90 \%$ of their parents) believed they would not have achieved as much without participating in the program. Eleven percent (and 10\% of the parents) considered it difficult to estimate program impact or felt that there was no impact.

Eighty-three percent of the Olympians (and $85 \%$ of their parents) credit the Math Olympiad program with increasing their educational opportunities. Six percent of the Olympians (and 15\% of their parents) said there was no increase in educational opportunities.

Slightly more than $91 \%$ of the Olympians (and $90 \%$ of the parents) stated that the Math Olympiad program helped them understand and appreciate their own ability; about six percent considered it neither helped nor hindered and $2.9 \%$ considered it a hindrance. Ten percent of the parents did not give any answer.

The results indicate that $77 \%$ of the Olympians (and $80 \%$ of the parents) considered that the

Table 5.5

Learning Achievements of the Olympians Before Graduation in Senior Middle School (\%)

\begin{tabular}{lccccccc}
\hline Grades & Chinese & Math & Physics & Chemistry & Biology & Foreign language & Total score \\
\hline Excellent & 35 & 100 & 90 & 55 & 50 & 35 & 60.8 \\
Good & 55 & 0 & 10 & 40 & 40 & 65 & 35.0 \\
Average & 10 & 0 & 0 & 5 & 10 & 0 & 4.2 \\
Poor & 0 & 0 & 0 & 0 & 0 & 0 & 0 \\
\hline
\end{tabular}

Excellent $=90-100$, good $=75-89$, average $=60-74$, poor $=59$ or under 
Table 5.6

Age at High School Graduation

\begin{tabular}{llllll}
\hline Age & 15 & 16 & 17 & 18 & 19 \\
\hline Number & 1 & 0 & 13 & 15 & 4 \\
$\%$ & 3.0 & 0 & 39.4 & 45.4 & 12.1 \\
\hline
\end{tabular}

Table 5.7

Microcomputer Used (\%)

\begin{tabular}{ll}
\hline Word processing & 9.0 \\
Math/statistics & 6.0 \\
Spread sheet & 0 \\
Internet & 0 \\
Database & 6.0 \\
Games & 11.0 \\
Graphics & 0 \\
Desktop publishing & 0 \\
\hline
\end{tabular}

Math Olympiad program had positively changed the attitude of others. The change in attitudes of the Olympians after participating in the Math Olympiad program can be seen in Table 5.8. Sixty percent of the Olympians report no negative effects from participation, whereas $40 \%$ consider there were some negative effects, such as strain and pressure. Twenty-three percent of the Olympians felt the competition exhausted them.

Table 5.8

Participation in Program Changed Olympians' Attitudes (\%)

\begin{tabular}{lcc}
\hline Item & Olympians & Parents \\
\hline Learning & 74 & \\
Positive changes & 14 & 77.7 \\
No change & 11 & 16.7 \\
Negative changes & & 5.6 \\
Math & 80 & 89 \\
Positive changes & 8.6 & 5.5 \\
No change & 11.4 & 5.5 \\
Negative changes & & \\
Science & 77 & 72 \\
Positive changes & 11 & 17 \\
No change & 9 & 5.5 \\
Negative changes & 3 & 5.5 \\
Missing & & 66.6 \\
College & 57 & 22.2 \\
Positive changes & 20 & 0 \\
No change & 17 & 11.1 \\
Negative changes & 6 & \\
Missing & & \\
\hline
\end{tabular}




\section{Influencing Factors}

Eighty-six percent of the Olympians consider the most influential person responsible for the development of their math talent was their teacher $(50 \%)$, while $36.1 \%$ consider their parents to be the most influential (see Table 5.9). Table 5.10 shows the results of the parents' perceptions of

Table 5.9

The Most Influential Person to Math Talent of the Olympians (\%)

\begin{tabular}{lccc}
\hline Parent & Teacher & Himself & None \\
\hline 36.1 & 50.0 & 5.6 & 8.3 \\
\hline
\end{tabular}

Table 5.10

Home Factors Influencing Olympian's Talent

\begin{tabular}{lcccc}
\hline & \multicolumn{2}{c}{ Mothers' perceptions } & \multicolumn{2}{c}{ Father's perceptions } \\
Factor & M & SD & M & SD \\
\hline Pressure & 2.44 & 0.49 & 2.50 & 0.49 \\
Psychologial support & 3.80 & 0.48 & 3.67 & 0.57 \\
Parental help & 3.16 & 0.90 & 3.06 & 0.92 \\
Press for Intell. Dev. & 3.74 & 1.13 & 3.85 & 1.10 \\
Monitoring & 3.44 & 1.10 & 3.42 & 1.13 \\
\hline
\end{tabular}

Table 5.11

Olympians' Self-concepts and Attributions

\begin{tabular}{lll}
\hline Factor & M & SD \\
\hline Math self-concept & 3.70 & 0.49 \\
Science self-concept & 3.25 & 0.40 \\
General self-concept & 3.78 & 0.60 \\
Effort attribution & 3.55 & 0.40 \\
Ability attribution & 2.80 & 0.41 \\
\hline
\end{tabular}

their influence. Psychological support and the press for intellectual development are more important than the other parental factors.

According to the results of the Self-confidence and attitude attribute Scales, general self-concept, math self-concept, and science self-concept were all high. Effort attributions were higher than ability attributions, which indicate that the Olympians consider personal effort to be more important than ability (see Table 5.11).

\section{Discussion}

The results of the study suggest three main conclusions. These are discussed in this closing section. 


\section{Development of Math Talent}

According to responses given by the Olympians and their parents, the Olympians became interested in mathematics very early in their lives (see Table 5.12). More than three-quarters of

Table 5.12

Age When the Olympians Began to be Interested in Mathematics (\%)

\begin{tabular}{lcccc}
\hline Age stage & Preschool & Primary School & Junior Middle School & Senior Middle School \\
\hline Olympians & 20.6 & 55.9 & 20.6 & 2.9 \\
Parents & 45.5 & 54.5 & 0 & 0 \\
\hline
\end{tabular}

Olympians: 34, parents: 22.

the Olympians became interested in math during their primary school years or before they started school. Referring back to Table 5.4, one can see that most parents discovered the Olympians' math talent during the primary school and junior high school years (76\%). Perhaps the main reason for their delayed recognition is due to the time of their birth $-80 \%$ were born before 1975. The special education for intellectually gifted/math talented children began only after 1978 (Zha, 1993). At that time parents did not give sufficient attention to the early education of their children. According to this study, only $40.9 \%$ of the parents gave the Olympians rudimentary education in mathematics when they were young.

The main manifestations of math talent of the Olympians were that they liked mathematics and had self-confidence in their math abilities, achieved "excellent" grades in mathematics, and were the highest in achievement in mathematics contests. More than $50 \%$ received prizes and medals many times in primary and middle school math contests, and 100\% won medals in IMO or CMO.

\section{Factors Accelerating the Development of Math Talent}

Based on the results of this study, the development of math talent involves the combination of many factors. The main factors accelerating the development of the Olympians' math talent are the positive home atmosphere and the parents' influence on early education, a solid foundation in education and the guidance of good teachers, encouragement and tempering of the contest activity, and the psychological stability and effort of the Olympians. The appropriate combination of these four aspects accelerated the development of the Olympians' mathematical talent.

Different facets have different influences on the Olympians. These facets are essentially common factors that promote the development of all kinds of gifted/talented children (Zha, 1994).

Parents stimulate the interest of the Olympians in mathematics through imperceptible influences such as the father's positive encouragement, parents' expectations (especially hoping that the child could enter key universities), concern about the child's studying, establishing a good family atmosphere for learning and studying, having many books at home that can arouse the child's interest in mathematics, encouragement to study hard, concern about the achievement of the child, and insistence that the child finish his homework every day. 
Most Olympians came from key middle schools that provided them with a solid educational foundation. Seventy-five percent had chances to enter gifted classes in high school or other after-school groups that had special education; $77.8 \%$ of them said they had been instructed by excellent teachers; and $75 \%$ reported benefitting from the teacher in charge of the gifted class.

Almost $90 \%$ of the Olympians attributed their present mathematics achievement to the Math Olympiad program. They considered the participation in mathematical group training to be helpful and believed that the Math Olympiad program stimulated their interest in mathematics and accelerated their positive change in attitude toward math and science.

Finally, the Olympians have developed a commitment toward learning mathematics. For example, they are interested in mathematics, like to solve mathematical problems, and have confidence in learning. Very few of them missed any class unless for special reasons; more than $80 \%$ believe that good achievement depends upon diligence and effort.

\section{Evaluation of the Math Olympiad Program}

Middle school mathematics contests have been launched rather early in some countries. In 1959 the first International Math Olympiad was held in Romania, and from then on every year this kind of competition has been held (Pu, 1995). Yet Mainland Chinese Olympians participated for the first time in 1985, over a quarter century later. Although these participants do not have a long history of participation, their achievements are outstanding. Chinese adolescents have great potential in mathematics and the overall standard of high achievement in mathematics in China is swiftly rising.

In the last ten years in Mainland China a "pyramid Math Olympiad selection system" has been established. Different stages of coaching are delineated. A "three combination" team of coaches consisting of excellent mathematics teachers and research workers play an important role in fostering the Olympians' development. All the Olympians that have been studied were instructed by senior coaches and attended lectures and training classes given by more than thirty senior coaches (Tao, Lui, \& Zha, 1995).

Every year 10 million middle school students participate in the mathematics contests. Through the selection process, the student's interest is encouraged; competitiveness and initiative strengthened; capacity to think independently and accurately is encouraged; flexibility and alertness are fostered; ability to solve problems creatively promoted; and persistent character is tempered. The Math Olympiads are helpful in discovering talented math personnel and have positive effects on educational reform, which raises the level of performance of teachers as well. These positive aspects of the Math Olympiad program are consistent with the reactions of the Olympians and their family members.

As to whether there are any negative effects of participating in the Math Olympiad, $40 \%$ of the Olympians feel there are some. They point to two aspects. First, there is certain degree of focusing on one subject. Some said because too much time was spent on mathematics, the learning of Chinese and foreign languages was hindered. Second, some experienced psychological pressure. There was too much stress; they were afraid of failure. Some expressed solitary feelings. These problems have already received attention, and measures for improvement have been adopted.

Another question was uncovered in this study - after the Olympians obtain prizes, how 
should their talent be further developed? The Olympians in this study could not get special guidance from their teachers after entering their university. This is a problem that needs to be adpressed in the future.

\section{References}

Pu Minya (1995). The origin and development of the Math Olympiad. Modern Special Education, 2, 35-36.

Tao Xiaoyong, Liu Pengzhi, \& Zha Zixiu (1995). Training competitors for IMO in Mainland China - Importance of school, family and society. Paper Presented at Post Conference China Meeting of 11 th World Council Gifted and Talented Children, Beijing.

Zha Zixiu (1993). Programs and practices for identifying and nurturing giftedness and talent in the People's Republic of China. In K. A. Heller, F. J. Morks \& A. H. Passow (Eds.), International handbook of research and development of giftedness and talent (pp. 809-814). New York: Pergamon Press.

Zha Zixiu (1994). Fifteen years of study on the psychology and education of gifted children. Acta Psychologica Sinica, 26 (4), 337-346.

Zhou Ping, \& Lu Ganqi (1995). The 2Ist century is called gifted and talented adolescents. Beijing: Meteorology Publishing House.

\section{Biographies}

Zha Zixiu graduated from Jinling University (Najing, China). Her research interests include development psychology and the study of gifted children. She is the Director of the Center for Gifted Children at the Institute of Psychology, Chinese Academy of Sciences and the Leader of the Supernormal Children's Cooperative Research Group of China. Her contribution to research concerning Chinese gifted children has won her numerous awards. She is the author or co-author of 9 books and more than 60 research papers and articles.

Liu Pengzhi graduated from the Faculty of Mathematics, Beijing Institute of Education. She is a Vice-Principal of the high school attached to the People's University of China and the Principal of Hua Luogeng School. She is a senior math teacher and a senior coach for the National Math Olympiad. She has authored numerous school-level text books and reference books in mathematics.

Tao Xiaoyong graduated from the Faculty of Mathematics, Beijing Capital Normal University. $\mathrm{He}$ is an Associate Professor in the Mathematical Faculty of the Beijing Institute of Education. He is also the Secretary General of the Beijing Mathematical Olympiad Development Center, Deputy Department Head of the Secondary Education Committee in the Beijing Mathematical Society, and a senior coach for the National Math Olympiad training squad. He is the author of several Chinese junior college-level math texts and competition math reference books. 